\title{
Article \\ Post-Acute COVID-19 Symptoms, a Potential Link with Myalgic Encephalomyelitis/Chronic Fatigue Syndrome: A 6-Month Survey in a Mexican Cohort
}

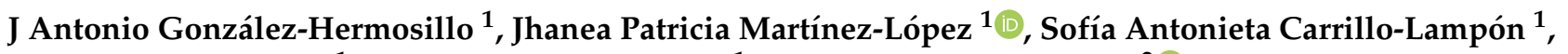

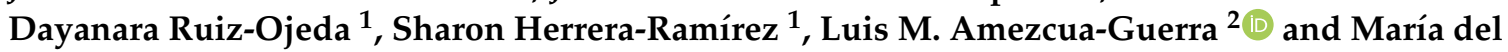 \\ Rocío Martínez-Alvarado ${ }^{3, *}$ (D) \\ 1 Department of Cardiovascular Dysautonomia, Instituto Nacional de Cardiología Ignacio Chávez, \\ Mexico City 14080, Mexico; sincope39@yahoo.com.mx (J.A.G.-H.); jhaneaml@gmail.com (J.P.M.-L.); \\ sofia.clampon@gmail.com (S.A.C.-L.); daayziur@gmail.com (D.R.-O.); sharon.herram@gmail.com (S.H.-R.) \\ 2 Department of Immunology, Instituto Nacional de Cardiología Ignacio Chávez, Mexico City 14080, Mexico; \\ lmamezcuag@gmail.com \\ 3 Department of Endocrinology, Instituto Nacional de Cardiología Ignacio Chávez, Mexico City 14080, Mexico \\ * Correspondence: orssino@yahoo.com
}

Citation: González-Hermosillo, JA.; Martínez-López, J.P.;

Carrillo-Lampón, S.A.; Ruiz-Ojeda,

D.; Herrera-Ramírez, S.;

Amezcua-Guerra, L.M.;

Martínez-Alvarado, M.d.R.

Post-Acute COVID-19 Symptoms, a

Potential Link with Myalgic

Encephalomyelitis/Chronic Fatigue Syndrome: A 6-Month Survey in a Mexican Cohort. Brain Sci. 2021, 11, 760. https://doi.org/10.3390/

brainsci11060760

Academic Editor: Thorsten Rudroff

Received: 3 May 2021

Accepted: 4 June 2021

Published: 8 June 2021

Publisher's Note: MDPI stays neutral with regard to jurisdictional claims in published maps and institutional affiliations.

Copyright: (C) 2021 by the authors. Licensee MDPI, Basel, Switzerland. This article is an open access article distributed under the terms and conditions of the Creative Commons Attribution (CC BY) license (https:// creativecommons.org/licenses/by/ $4.0 /)$.
Abstract: The aim of this study was to describe the clinical evolution during 6 months of follow-up of adults recovered from COVID-19. We tried to determine how many met the definition of Myalgic Encephalomyelitis/Chronic Fatigue Syndrome (ME/CFS). A total of 130 patients (51.0 \pm 14 years, $34.6 \%$ female) were enrolled. Symptoms were common, participants reported a median number of 9 (IQR 5-14) symptoms. Fatigue was the most common symptom $(61 / 130 ; 46.9 \%)$. Patients with fatigue were older $53.9 \pm 13.5$ years compared with $48.5 \pm 13.3$ years in those without fatigue $(p=0.02)$ and had a longer length of hospital stay, $17 \pm 14$ days vs. $13 \pm 10$ days $(p=0.04)$. There was no difference in other comorbidities between patients with fatigue and those without it, and no association between COVID-19 severity and fatigue. After multivariate adjustment of all baseline clinical features, only age 40 to 50 years old was positively associated with fatigue, OR 2.5 ( $95 \%$ CI 1.05-6.05) $p=0.03$. In our survey, only 17 (13\%) patients met the Institute of Medicine's criteria for "systemic exertion intolerance disease," the new name of ME/CFS. In conclusion, in some patients, the features of post-acute COVID-19 syndrome overlap with the clinical features of ME/CFS.

Keywords: fatigue; symptoms of COVID-19; Myalgic Encephalomyelitis/Chronic Fatigue Syndrome

\section{Introduction}

In March 2020, the severe acute respiratory syndrome coronavirus 2 (SARS-CoV-2) was declared a global pandemic by the World Health Organization. Mexico has been one of the worst affected countries with over 2,319,519 confirmed cases and 214,095 deaths related to SARS-CoV-2 until 23 April 2021. The epidemiological, clinical characteristics, pathogenesis, and complications of patients with COVID-19 at acute phase have been well described. An increasing number of apparently cured people are being discharged from hospitals following COVID-19 infection. However, the prevalence, mechanisms, nature and duration of symptoms in convalescent survivors remain largely unknown. There has been recent interest in the so-called post-acute sequelae of SARS-CoV-2 syndrome, long COVID, long-haul post-COVID-19, post-COVID fatigue, viral syndrome post-COVID-19, post-acute COVID-19, post-COVID-19 neurological syndrome, or post-COVID-19 syndrome, whereby patients have persistence of a multitude of symptoms following initial infection resolution. Only a few studies have systematically investigated the symptoms in the recovery of COVID-19 survivors, but the dynamic changes of these remain largely unknown [1-6].

Furthermore, it has not yet been well established if gender, age, underlying diseases, viral load, or duration of COVID-19 significantly increase the risk of developing long-term 
effects of COVID-19. Series have reported the incidence of persistent symptoms ranging from $40 \%$ to $90 \%$ of patients, but the interpretation of results is hampered by non-systematic and short-term evaluations, with high heterogeneity in relation to age, severity of infection, follow-up, and characteristics of the clinical evaluation [4].

Severe acute respiratory syndrome (SARS) and Middle East respiratory syndrome (MERS) are two other major coronavirus disease outbreaks that have occurred in the 21st century. Alongside acute challenges, the SARS and MERS outbreaks resulted in a chronic post-viral syndrome characterized by chronic fatigue, nonspecific myalgia, depression, sleep disturbances, and reduced ability to exercise in some survivors up to 6 months after discharge from hospital [7]. To date, it remains unknown whether and to what extent symptom burden in post-COVID-19 is comparable with symptom burden in other post-infection syndromes.

Persistent symptoms in hospitalized and non-hospitalized patients with COVID-19, regardless of severity of initial infection, have been observed at 3 and 6 months after a SARS-CoV-2 infection $[6,8,9]$. Fatigue is the most common symptom of acute and long COVID-19, which is not associated with severity of initial infection, although the underlying mechanisms are unclear [9]. It is present even after 6 months of the first symptom of acute COVID-19 with a prevalence of 58-63\% [10]. Similar to other post-viral/ infectious syndromes, COVID-19 appears to result in symptoms that outlast the initial acute illness [11,12]. Symptoms observed in post COVID-19 patients resemble Myalgic Encephalomyelitis/Chronic Fatigue Syndrome (ME/CFS), a complex, controversial, common, and debilitating clinical condition of unknown origin, which has largely been diagnosed using consensus-based case definitions [13-17]. An international online survey of 3762 patients who, by self-report, experienced symptoms consistent with COVID-19, showed at 7 months after the onset of the illness that $77.9 \%$ remained with fatigue [18]. Townsed et al. studied 128 confirmed COVID-19 patients and found that, at a median of 10 weeks after the initial COVID-19 symptoms, 52\% reported persistent fatigue and 31\% had not returned to work [9].

Even though the exact mechanism that underlies ME/CFS has not been fully elucidated, evidence for a somatic origin of the disease is accumulating. ME/CFS often starts after an infection. It has been suggested that the infection initiates in genetically predisposed individuals to a chronic auto-reactive process, which affects several functions, including brain and energy metabolism. Recently, the U.S. National Academies of Sciences, Engineering and Medicine recommended a new name for ME/CFS, "systemic exhaustion intolerance disease" (SEID) [15]. The case definition of ME/CFS requires that the illness must have lasted for at least 6 months.

Studying the long-term symptoms of COVID-19 is critical for understanding the full natural history of disease and accurately predicting the cumulative impact of disease beyond hospitalization and mortality. The reported data does not allow determining how many patients with COVID-19 meet the ME/CFS criteria, but it is plausible that in the future as the number of infected people increases, we will see substantial growth in the number of cases with ME/CFS [19,20]. Perrin et al. [21] proposed that, as happened after the SARS outbreak, a proportion of COVID-19 affected patients might develop a severe post-COVID-19 syndrome characterized by long-term symptoms resembling ME/CFS.

COVID-19 not only threatens people's physical health but also could affect their mental health. Casagrande et al., conducted an online survey in 2291 patients, 57.1\% of participants reported poor sleep quality, 32.1\% high anxiety, $41.8 \%$ high distress, and 7.6\% post-traumatic stress disorder linked to COVID-19 [22]. Moreover, Cortés-Alvarez et al. published an online survey of 1105 individuals from 32 states in Mexico; 15.7\% reported moderate-severe depressive symptoms, $22.6 \%$ reported moderate-severe anxiety symptoms, and 19.8\% reported moderate-severe stress levels [23].

The primary aim of this study was to describe the prevalence, nature, evolution and potential risk factors of symptoms in patients discharged to home after hospitalization for moderate to severe COVID-19. For the purpose of this study, we defined post-acute COVID- 
19 as persistent symptoms beyond 12 weeks from the onset of COVID-19 infection [24]. Secondarily, we tried to determine in this cohort how many individuals met the case definition of ME/CFS for at least 6 months. We also sought to investigate whether there was a relationship between fatigue and a variety of clinicopathological parameters.

\section{Materials and Methods}

\subsection{Study Cohort}

This single-center prospective longitudinal study was carried out in our SARS-CoV-2 referral university hospital in Mexico City, Mexico. We enrolled consecutive adult patients hospitalized with moderate to severe confirmed COVID-19 pneumonia at hospital admission. Patients were classified according to the World Health Organization (WHO) guidelines; moderate disease was defined as clinical signs of pneumonia, such as fever, cough, dyspnea, and/or tachypnea, but no signs of severe pneumonia and, in particular, an oxygen saturation $(\mathrm{SaO} 2) \geq 90 \%$ on room air; severe disease was defined as clinical signs of pneumonia plus one of the following: respiratory rate $>30$ breaths $/ \mathrm{min}$, severe respiratory distress, or $\mathrm{SaO} 2<90 \%$ on room air [25]. A total of 225 patients were admitted with a confirmed diagnosis from 11 April 2020 to 15 September 2020, and 160 were cured and discharged from the hospital by 22 September 2020. Thus, the time frame from the discharge of the hospital to the follow-up completion on 22 March 2021 was 6 months. All patients included in this cohort had a positive real-time reverse transcription-polymerase chain reaction (PCR) test, routine blood workup (including complete blood count, inflammatory markers, and metabolic panel). Diagnosis of COVID-19 pneumonia was performed by chest computed tomography scan in 96 (60\%) patients or chest x-ray in 64 (40\%) patients. All of them required supplemental oxygen. Twenty-nine patients $(22 \%)$ required mechanical ventilation in the intensive care unit (ICU) with a mean of $15 \pm 11$ days of respiratory support.

Since fatigue is recognized as one of the most common presenting symptoms in individuals infected with SARS-CoV-2 and given that concerns have been raised that it has the potential to trigger a post-viral fatigue syndrome, we categorized our participants according to the presence or absence of fatigue. It was defined in accordance with the $\mathrm{ME} / \mathrm{CFS}$ criteria (a symptom which is not the result of ongoing exertion, is not relieved by rest, occurs after minimal physical or mental/cognitive exertion and is medically unexplained) [26].

An informed consent was waived due to the minimal risk characteristics of an observational study.

\subsection{Data Collection}

Data regarding demographic, clinical characteristics, pre-existing relevant comorbidities considered to confer high risk for severe COVID-19, and laboratory findings were retrieved from the electronic medical records. We excluded the following patients: 1 . Those who died before the follow-up started, 2 . Those who declined to participate, 3 . Those unable to be contacted. The remaining 130 survivors were contacted by phone by trained physicians and were asked to answer a previously designed questionnaire with a checklist of symptoms. Participants were asked a binary question regarding symptoms within six possible ME/CFS domains by organ system, according to the International Consensus Criteria published in 2011 [14]: 1. Fatigue and dyspnea (manifested at rest or post exertional), 2. Neurocognitive and neurosensory dysfunction, (concentration impairment, short-term memory loss), 3. Sleep dysfunction (sleeping disturbances, unrefreshing sleep), 4. Autonomic dysregulation (postural dizziness, lightheadedness, tachycardia, chest pain, temperature intolerance, sweating alterations, gastrointestinal, and genitourinary disturbances), 5. Pain disturbances (headache, joint and muscle pain), and 6. Psychiatric (anxiety, depression), in comparison to their pre-COVID-19 (baseline) status. Any remaining or newly occurring symptoms at 3 and 6 months after discharge from the hospital were recorded. The survivor's current symptoms were distinguished from those of their pre- 
COVID-19 acute phase. The course of each symptom during follow-up was documented in detail.

\subsection{Statistical Analysis}

Descriptive statistical analysis was performed for all variables. Continuous variables were presented as mean (standard deviation, SD) or median (interquartile range, IQR), and dichotomous variables were expressed as absolute frequencies (percentage). Group comparisons were performed using Student's $t$-test or Mann-Whitney U test for continuous variables and the Chi-squared test or Fisher's exact test for categorical variables. To investigate the impact of individual variables on the presence of residual fatigue after hospitalization, participants were categorized into two groups according to fatigue. To compare fatigue at 3 months and 6 months we used Chi-squared test or Fisher's exact test for categorical variables. Demographic data, comorbidities, body mass index (BMI), clinical data, and laboratory values at admission were included as predictors of fatigue. Multivariable adjusted logistic regression models were used to estimate the odds ratios (ORs) and 95\% confidence intervals (CIs) for association between fatigue and risk factors. All tests were two-sided, and a $p$-value less than 0.05 was considered statistically significant. We included all participants for whom the variables of interest were available in the final analysis, without missing data. All statistical analyses were done with SPSS v. 15.

\section{Results}

\subsection{Study Population}

During the study period, a total of 767 consecutive patients were evaluated in the dedicated triage unit for suspected SARS-CoV-2 infection; of them, 225 (29.3\%) were admitted with a diagnosis of confirmed SARS-CoV-2 pneumonia (a detailed flowchart of the study design is shown in Figure 1. Sixty-five patients (28.8\%) died during hospitalization and $160(71.1 \%)$ were discharged after recovery and eligible for the follow-up post-acute care assessment. Three patients $(1.8 \%)$ refused to participate and $27(16.8 \%)$ could not be contacted. Finally, 130 patients were successfully followed up and considered as the study cohort.

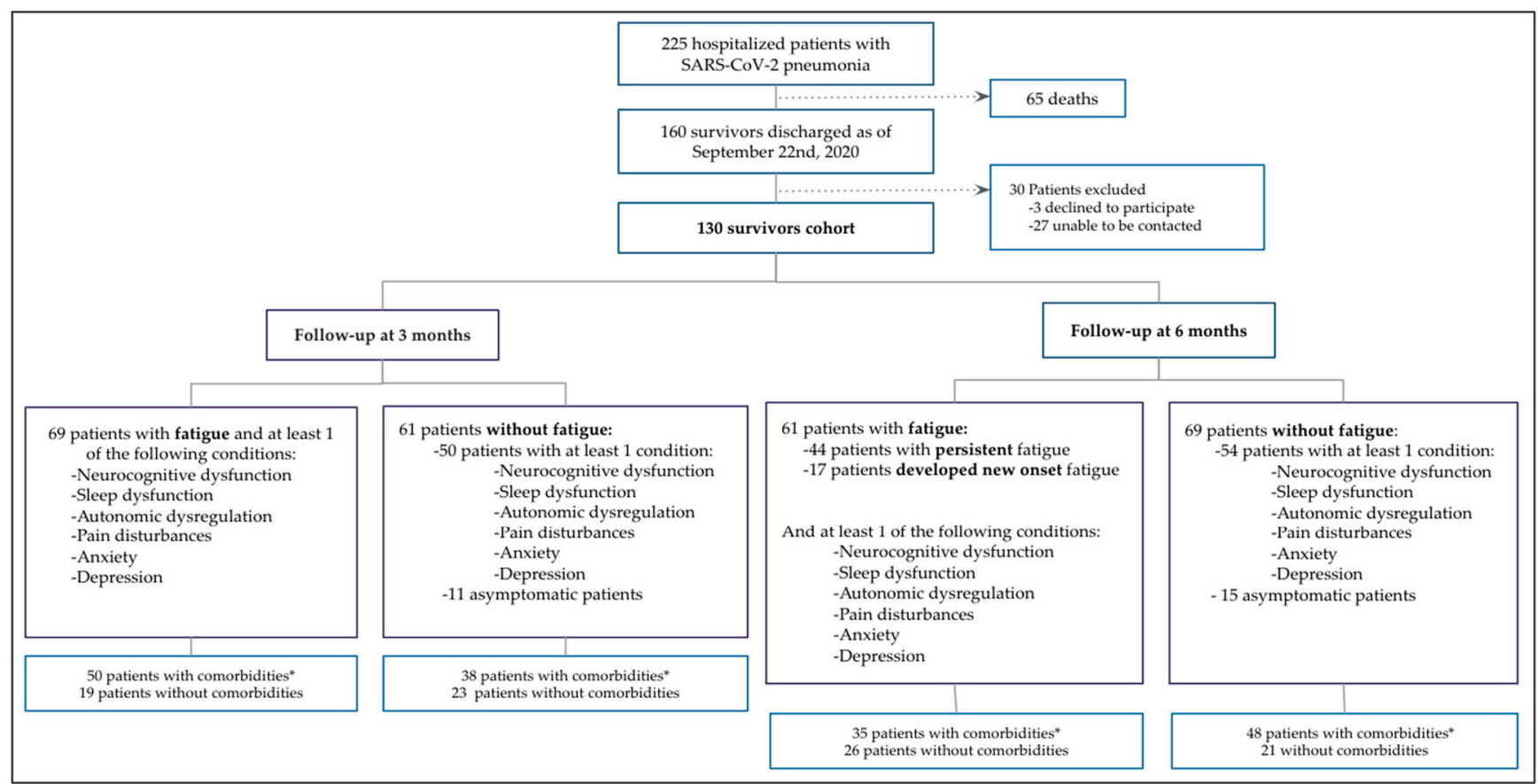

Figure 1. Flow Chart of the Study Design. * Comorbidities: Hypertension, Diabetes, Chronic obstructive pulmonary disease, Chronic Heart disease, Chronic Kidney disease, Immunosuppressive condition or Psychiatric disorder. 


\subsection{Demographics and Clinical Characteristics}

Baseline characteristics are summarized in Table 1 . The mean age of the 130 survivors was $51 \pm 14$ years, ranging from 18 to 80 years, $45(34.6 \%)$ were female. The most common comorbidity was hypertension in 53 (41\%) patients, followed by type 2 diabetes in $41(32 \%)$, and obesity in $38(29 \%)$. The mean duration of hospital stay was $15 \pm 12$ days. Laboratory findings at admission are presented in Table 1. Overall, inflammatory biomarkers were elevated. Patients acutely infected with SARS-CoV-2 demonstrated decreased lymphocyte counts, higher neutrophil counts, elevated C-reactive protein (CRP), ferritin, D-dimer, as well as pro-inflammatory cytokines such as interleukin-6 (IL-6) and vascular endothelial growth factor (VEGF).

Table 1. Demographic characteristics of study participants.

\begin{tabular}{|c|c|c|c|c|}
\hline Characteristic & $\begin{array}{c}\text { Overall } \\
(n=130)\end{array}$ & $\begin{array}{l}\text { Non-Fatigue } \\
\quad(n=61)\end{array}$ & $\begin{array}{l}\text { Fatigue } \\
(n=69)\end{array}$ & $p$-Value \\
\hline Age (years) & $51.0 \pm 14$ & $48.5 \pm 13.2$ & $53.0 \pm 13.5$ & 0.02 \\
\hline Female $n(\%)$ & $45(34.6)$ & $17(27.8)$ & $28(40.5)$ & 0.09 \\
\hline Active smoker $n(\%)$ & $23(17.6)$ & $12(19.6)$ & $11(15.6)$ & 0.3 \\
\hline Body Mass Index $\left(\mathrm{kg} / \mathrm{m}^{2}\right)$ & $26.6 \pm 3$ & $27.6 \pm 3.8$ & $28.2 \pm 5.1$ & 0.5 \\
\hline \multicolumn{5}{|c|}{ Underlying Diseases $n(\%)$} \\
\hline Hypertension & $53(40.7)$ & $22(36.0)$ & $31(44.9)$ & 0.19 \\
\hline Overweight & $62(47.6)$ & $35(57.3)$ & $27(39.1)$ & 0.11 \\
\hline Obesity & $38(29.2)$ & $13(21.3)$ & $25(36.2)$ & 0.10 \\
\hline Diabetes & $41(31.5)$ & $17(27.8)$ & $24(34.7)$ & 0.25 \\
\hline Chronic heart disease & $22(16.9)$ & $9(14.7)$ & $13(18.8)$ & 0.35 \\
\hline Chronic obstructive pulmonary disease & $4(3.0)$ & $1(1.6)$ & $3(4.3)$ & 0.35 \\
\hline Chronic kidney disease & $14(10.7)$ & $5(8.1)$ & $9(13.0)$ & 0.27 \\
\hline Immunosuppressive condition & $15(11.5)$ & $7(11.4)$ & $8(11.5)$ & 0.6 \\
\hline Psychiatric disorder & $2(1.5)$ & 0 & $2(2.8)$ & 0.28 \\
\hline \multicolumn{5}{|c|}{ Acute COVID-19 Characteristics } \\
\hline Mechanical ventilation $n(\%)$ & $29(22.3)$ & $12(19.6)$ & $17(24.6)$ & 0.32 \\
\hline Days on mechanical ventilation & $15 \pm 11$ & $14 \pm 10.5$ & $15 \pm 12$ & 0.83 \\
\hline Length of hospital stay in days & $15 \pm 12$ & $13 \pm 10$ & $17 \pm 14$ & 0.04 \\
\hline Days of follow-up since discharge & $270 \pm 32$ & $266 \pm 30$ & $273 \pm 36$ & 0.8 \\
\hline \multicolumn{5}{|c|}{ Laboratory Tests Median (IQR) } \\
\hline Ferritin ng/mL & $512(200-865)$ & $501(255-820)$ & $520(162-880)$ & 0.73 \\
\hline NT-proBNP pg/mL & $242(89-1055)$ & $200(86-803)$ & $313(94-1803)$ & 0.23 \\
\hline Hs-cTnI pg/mL & $9.2(4.7-23)$ & $6.8(4.7-18.5)$ & $11.4(4.8-25.4)$ & 0.26 \\
\hline D-Dimer ng/mL & $0.35(0.18-0.56)$ & $0.34(0.16-0.76)$ & $0.37(0.19-0.55)$ & 0.37 \\
\hline CRP mg/L & $121(53.7-216.5)$ & $121(57.8-217)$ & 123.5 (42.5-218.7) & 0.86 \\
\hline Fibrinogen $\mathrm{g} / \mathrm{L}$ & $5.26(4.49-6)$ & $5.5(4.8-6)$ & $5.09(4.3-6)$ & 0.16 \\
\hline IL-6 pg/mL & $4.5(4.5-44.5)$ & $7.9(4.5-64)$ & $4.5(4.5-39.5)$ & 0.63 \\
\hline VEGF $\mathrm{pg} / \mathrm{mL}$ & $53.2(15-123.1)$ & $46.6(15-119)$ & $60.6(15-129.6)$ & 0.74 \\
\hline Neutrophil count, $10^{3} / \mathrm{L}$ & $6.7(4.1-10.5)$ & $6.7(4.5-11.6)$ & $6.8(4.1-9)$ & 0.30 \\
\hline Lymphocyte count, $10^{3} / \mathrm{L}$ & $0.8(0.6-1.2)$ & $0.9(0.6-1.2)$ & $0.8(0.6-1.2)$ & 0.83 \\
\hline AST U/L & $36(22.3-57.9)$ & $36(22.2-58.7)$ & $37.2(22.1-56.5)$ & 0.80 \\
\hline Glucose mg/dL & $122(105-153)$ & $120(105.4-153)$ & $125(104-153)$ & 0.81 \\
\hline Creatinine $\mathrm{mg} / \mathrm{dL}$ & $0.9(0.73-1.2)$ & $0.9(0.72-1.24)$ & $0.9(0.73-1.28)$ & 0.69 \\
\hline
\end{tabular}

Data are presented as $n$ (\%) or median (Interquartile range): $p$ values were calculated by $t$-student, Chi-square, Mann-Whitney U-test. High sensitive cardiac Troponin I (hs-cTnI), C-Reactive Protein (CRP), Interleukin-6 (IL-6), Vascular Endothelial Growth Factor (VEGF), Aspartate Aminotransferase (AST).

Three months after discharge from the hospital, 119 (91.5\%) patients had persistence of at least one symptom that did not exist before COVID-19 with a median of 9 (IQR 4-13) symptoms and at 6 months of follow-up, $115(88 \%)$ patients reported at least one symptom with a median of 9 (IQR 5-14) symptoms. 
As expected, fatigue was the most frequently persistent symptom at 3 months followup, reported by 69 (53\%) patients. There were some significant demographic differences in those patients with or without fatigue. Patients with fatigue at three months follow-up were older, $53.9 \pm 13.5$ years compared with $48.5 \pm 13.3$ years in those without fatigue ( $p=0.02)$ and had a longer length of hospital stay $17 \pm 14$ days vs. $13 \pm 10$ days $(p=0.04)$, although their distribution by gender was similar. Twenty-eight $(40.5 \%)$ patients with fatigue were females compared with $17(27.8 \%)$ without fatigue $(p=0.09)$. There was no difference in BMI between patients with fatigue and those without it. Overall, the remaining most prevalent symptoms at three months follow-up were: dyspnea on effort $66(50.8 \%)$, short-term memory loss 59 (45.4\%), sleep disturbances 59 (45.4\%), myalgias 53 (40.8\%), tachycardia $53(40.8 \%)$, postural dizziness 51 (39.2\%), anxiety 51 (39.2\%), depression 46 $(35.3 \%)$, and joint pain in $50(38.5 \%)$ patients (Table 2$)$. The rate of post-COVID fatigue decreased over time since only $61(46.9 \%)$ patients reported this symptom after 6 months.

As shown in Table 2, on univariate analysis of differences in those with and without fatigue at three months follow-up, there was a significantly higher prevalence of symptoms in those with fatigue: dyspnea in $44(63.8 \%)$, tachycardia in $36(52.2 \%)$, sleep disturbances in $41(59.4 \%)$, postural dizziness in $31(44.9 \%)$, constipation in $35(50.7 \%)$, muscle pain in $39(56.5 \%)$ and joint pain in $34(49.3 \%)$, all of them with high statistical significance. In patients with persistent fatigue at six months follow-up, a significantly higher prevalence of the majority of symptoms was also reported.

There is a large discrepancy in the prevalence of ME/CFS as a result of using different definitions. The more specific the exclusion criteria in the definition, the smaller the number of patients diagnosed with ME/CFS. Based on the original criteria of ME/CFS proposed by the Centers for Disease Control and Prevention (CDC) Fukuda definition of 1994 [13], the only mandatory feature of ME/CFS is unexplained chronic fatigue, which must be accompanied by at least four out of eight minor symptoms related to neurological, cognitive, sleep, autonomic, gastrointestinal, and genitourinary disturbances, plus pain. In our survey, $23(17.6 \%)$ patients met this case definition criteria. The Canadian clinical case definition [14] specifies that post exertional malaise (a vague feeling of discomfort or fatigue) must occur with a loss of physical or mental stamina, muscle, or cognitive fatigability. In addition, there need to be two or more neurological/cognitive manifestations, (unrefreshing sleep or poor sleep quality), as well as a significant degree of arthralgia and/or myalgia. Finally, there needs to be at least one symptom from two of the following categories: autonomic manifestations (neurally mediated hypotension, postural orthostatic tachycardia, lightheadedness, palpitations with or without arrhythmias), neuroendocrine manifestations (recurrent feelings of feverishness and cold extremities), and immune manifestations (recurrent sore throats). Therefore, in our cohort, 20 (15.3\%) patients met these criteria. Compared with the International Consensus Criteria of 2011 [15], where a patient has to report at least eight (one mandatory: post-exertional neuroimmune exhaustion, and seven variable symptoms) to meet the diagnosis of $\mathrm{ME}$, while autonomic, sensory and cognitive dysfunctions are not compulsory; 25 (19.2\%) of our patients met the diagnosis criteria. The Institute of Medicine [16], recently proposed a new case definition that included the following 4 symptoms: substantial reduction or impairment in the ability to engage in pre-illness levels of occupational, educational, social, or personal activities; post-exertional malaise, unrefreshing sleep; and at least one of the two following symptoms: cognitive impairment or orthostatic intolerance. According to this definition, the presence of other illnesses should not preclude patients from receiving a diagnosis of ME/CFS (SEID) except in the event that all the symptoms can be accounted for by these other illnesses. Following the SEID case definition in our cohort, only 17 (13\%) patients met the criteria for ME/CFS. 
Table 2. Post-acute COVID-19 symptoms.

\begin{tabular}{|c|c|c|c|c|c|c|c|c|c|c|}
\hline Symptoms & $\begin{array}{c}\text { Overall } \\
(n=130)\end{array}$ & $\begin{array}{l}\text { Non-Fatigue } \\
\quad(n=61)\end{array}$ & $\begin{array}{l}\text { Fatigue } \\
(n=69)\end{array}$ & $p$-Value & Overall $(n=130)$ & $\begin{array}{c}\text { Non- } \\
\text { Fatigue } \\
(n=69)\end{array}$ & $\begin{array}{l}\text { Fatigue } \\
(n=61)\end{array}$ & $\begin{array}{l}\text { Non-Fatigue at } \\
3 \text { Months vs. } \\
\text { Non-Fatigue at } \\
6 \text { Months } \\
p \text {-Value }\end{array}$ & $p$-Value & $\begin{array}{c}\text { Fatigue at } 3 \\
\text { Months vs. } \\
\text { Fatigue at } 6 \\
\text { Months } \\
p \text {-Value }\end{array}$ \\
\hline Fatigue & $69(53.0)$ & 0 & $69(100)$ & $<0.001$ & $61(46.9)$ & 0 & $61(100)$ & $<0.001$ & 0.3 & 0.19 \\
\hline \multicolumn{11}{|c|}{ Respiratory } \\
\hline Resting dyspnea & $21(16.2)$ & $6(9.8)$ & $15(21.7)$ & 0.053 & $21(16.2)$ & $4(5.8)$ & $17(27.9)$ & 0.001 & 0.29 & 0.34 \\
\hline \multicolumn{11}{|c|}{ Neurocognitive, Neurosensory, Perceptual Disturbances } \\
\hline Concentration impairment & $30(23.1)$ & $8(13.1)$ & $22(31.9)$ & 0.009 & $40(30.8)$ & $10(14.5)$ & $30(49.2)$ & $<0.001$ & 0.51 & 0.05 \\
\hline Short-term memory loss & $59(45.4)$ & $17(27.9)$ & $36(52.2)$ & 0.004 & $70(53.8)$ & $29(42)$ & $41(67.2)$ & 0.003 & 0.06 & 0.08 \\
\hline Inability to focus vision & $50(38.5)$ & $18(29.5)$ & $34(49.3)$ & 0.017 & $43(33.1)$ & $13(18.8)$ & $30(49.2)$ & $<0.001$ & 0.11 & 0.56 \\
\hline Light sensitivity & $24(18.5)$ & $4(6.6)$ & $17(24.6)$ & 0.004 & $26(20.0)$ & $8(11.6)$ & $18(29.5)$ & 0.01 & 0.24 & 0.33 \\
\hline Anosmia & $16(12.3)$ & $3(4.9)$ & $11(15.9)$ & 0.039 & $9(6.9)$ & $4(5.8)$ & $5(8.2)$ & 0.42 & 0.56 & 0.14 \\
\hline Ageusia & $16(12.3)$ & $1(1.6)$ & $13(18.8)$ & 0.001 & $7(5.4)$ & $3(4.3)$ & $4(6.6)$ & 0.43 & 0.35 & 0.03 \\
\hline Tingling & $61(46.9)$ & $20(32.8)$ & $38(55.1)$ & 0.009 & $61(46.9)$ & $26(37.7)$ & $35(57.4)$ & 0.019 & 0.34 & 0.54 \\
\hline Disturbance of sleep & $59(45.4)$ & $17(27.9)$ & $41(59.4)$ & $<0.001$ & $66(50.8)$ & $28(40.6)$ & $38(62.3)$ & 0.011 & 0.09 & 0.43 \\
\hline Unrefreshin sleep & $50(38.4)$ & $15(24.6)$ & $31(44.9)$ & 0.012 & $63(48.5)$ & $25(36.2)$ & $38(62.3)$ & 0.003 & 0.1 & 0.03 \\
\hline \multicolumn{11}{|c|}{ Autonomic Dysregulation } \\
\hline Postural dizziness & $51(39.2)$ & $16(26.2)$ & $31(44.9)$ & 0.021 & $46(35.4)$ & $13(18.8)$ & $33(54.1)$ & $<0.001$ & 0.21 & 0.24 \\
\hline $\begin{array}{l}\text { Lightheadedness when } \\
\text { prolonged standing }\end{array}$ & $22(16.9)$ & 7 (11.5) & $15(21.7)$ & 0.092 & $22(16.9)$ & $7(10.1)$ & $15(24.6)$ & 0.025 & 0.51 & 0.51 \\
\hline Chest pain & $40(30.8)$ & $9(14.8)$ & $25(36.2)$ & 0.004 & $36(27.7)$ & $9(13)$ & $27(44.3)$ & $<0.001$ & 0.48 & 0.28 \\
\hline Tachycardia & $53(40.8)$ & $15(24.6)$ & $36(52.2)$ & 0.001 & $46(35.4)$ & $17(24.6)$ & $29(47.5)$ & 0.005 & 0.57 & 0.36 \\
\hline Change pattern of sweating & $47(36.2)$ & $17(27.9)$ & $26(37.7)$ & 0.159 & $37(28.5)$ & $11(15.9)$ & $26(42.6)$ & 0.001 & 0.07 & 0.34 \\
\hline Intolerance to temperature & $41(31.5)$ & $12(19.7)$ & $28(40.6)$ & 0.008 & $40(30.8)$ & $12(17.4)$ & $28(45.9)$ & $<0.001$ & 0.45 & 0.33 \\
\hline
\end{tabular}


Table 2. Cont.

\begin{tabular}{|c|c|c|c|c|c|c|c|c|c|c|}
\hline Symptoms & $\begin{array}{c}\text { Overall } \\
(n=130)\end{array}$ & $\begin{array}{l}\text { Non-Fatigue } \\
\quad(n=61)\end{array}$ & $\begin{array}{l}\text { Fatigue } \\
(n=69)\end{array}$ & $p$-Value & Overall $(n=130)$ & $\begin{array}{c}\text { Non- } \\
\text { Fatigue } \\
(n=69)\end{array}$ & $\begin{array}{l}\text { Fatigue } \\
(n=61)\end{array}$ & $\begin{array}{c}\text { Non-Fatigue at } \\
3 \text { Months vs. } \\
\text { Non-Fatigue at } \\
6 \text { Months } \\
p \text {-Value }\end{array}$ & $p$-Value & $\begin{array}{c}\text { Fatigue at } 3 \\
\text { Months vs. } \\
\text { Fatigue at } 6 \\
\text { Months } \\
p \text {-Value }\end{array}$ \\
\hline \multicolumn{11}{|c|}{ Gastrointestinal and Genitourinary } \\
\hline Stomach bloated after meals & $35(26.9)$ & $9(14.8)$ & $24(34.8)$ & 0.007 & $45(34.6)$ & $12(17.4)$ & $33(54.1)$ & $<0.001$ & 0.43 & 0.03 \\
\hline Abdominal pain & $20(15.4)$ & $5(8.2)$ & $13(18.8)$ & 0.065 & $20(15.4)$ & $3(4.3)$ & $17(27.8)$ & $<0.001$ & 0.29 & 0.15 \\
\hline Diarrhea & $19(14.6)$ & $6(9.8)$ & $13(18.8)$ & 0.114 & $19(14.6)$ & $6(8.7)$ & $13(21.3)$ & 0.03 & 0.62 & 0.44 \\
\hline Nausea & $19(14.6)$ & $3(4.9)$ & $16(23.2)$ & 0.003 & $22(16.9)$ & $5(7.2)$ & $17(27.8)$ & $<0.002$ & 0.43 & 0.42 \\
\hline Urinary frequency & $44(33.8)$ & $8(13.1)$ & $21(30.4)$ & 0.015 & $30(23.1)$ & $12(17.4)$ & $18(29.5)$ & 0.07 & 0.33 & 0.45 \\
\hline Difficulty emptying bladder & $18(13.8)$ & $6(9.8)$ & $14(20.3)$ & 0.07 & $14(10.7)$ & $4(5.8)$ & $10(16.4)$ & 0.02 & 0.29 & 0.36 \\
\hline Difficulty with sexual function & $28(21.5)$ & $9(14.8)$ & $17(24.6)$ & 0.117 & $18(13.8)$ & $8(11.6)$ & $10(16.4)$ & 0.29 & 0.39 & 0.17 \\
\hline \multicolumn{11}{|c|}{ Pain } \\
\hline Headache & $38(29.2)$ & $12(19.7)$ & $25(36.2)$ & 0.028 & $48(36.9)$ & $12(17.4)$ & $36(59)$ & $<0.001$ & 0.45 & 0.01 \\
\hline Muscle pain & $53(40.8)$ & $14(22.9)$ & $39(56.5)$ & $<0.001$ & $47(36.2)$ & $11(15.9)$ & $36(59)$ & $<0.001$ & 0.21 & 0.45 \\
\hline Joint pain & $50(38.5)$ & $11(18)$ & $34(49.3)$ & $<0.001$ & $57(43.8)$ & $18(26.1)$ & $39(63.9)$ & $<0.001$ & 0.18 & 0.06 \\
\hline Anxiety & $51(39.2)$ & $15(24.6)$ & $39(56.3)$ & $<0.001$ & $46(35.4)$ & $11(15.9)$ & $35(57.4)$ & $<0.001$ & 0.15 & 0.53 \\
\hline Depression & $46(35.3)$ & $13(21.3)$ & $31(44.9)$ & 0.004 & 45 (34.6) & $13(18.8)$ & $32(52.5)$ & $<0.001$ & 0.44 & 0.24 \\
\hline
\end{tabular}

Data are presented as $n(\%), p$ values were calculated by chi-square. 
After multivariate adjustment of all baseline clinical features and laboratory biomarkers, only age 40 to 50 years old was positively associated with fatigue with an OR 2.5 (95\% CI 1.05-6.05) $p=0.03$. A risk trend towards the female sex was observed, however it did not reach statistical significance, OR $1.95(0.94-4.06) p=0.07$ (Figure 2).

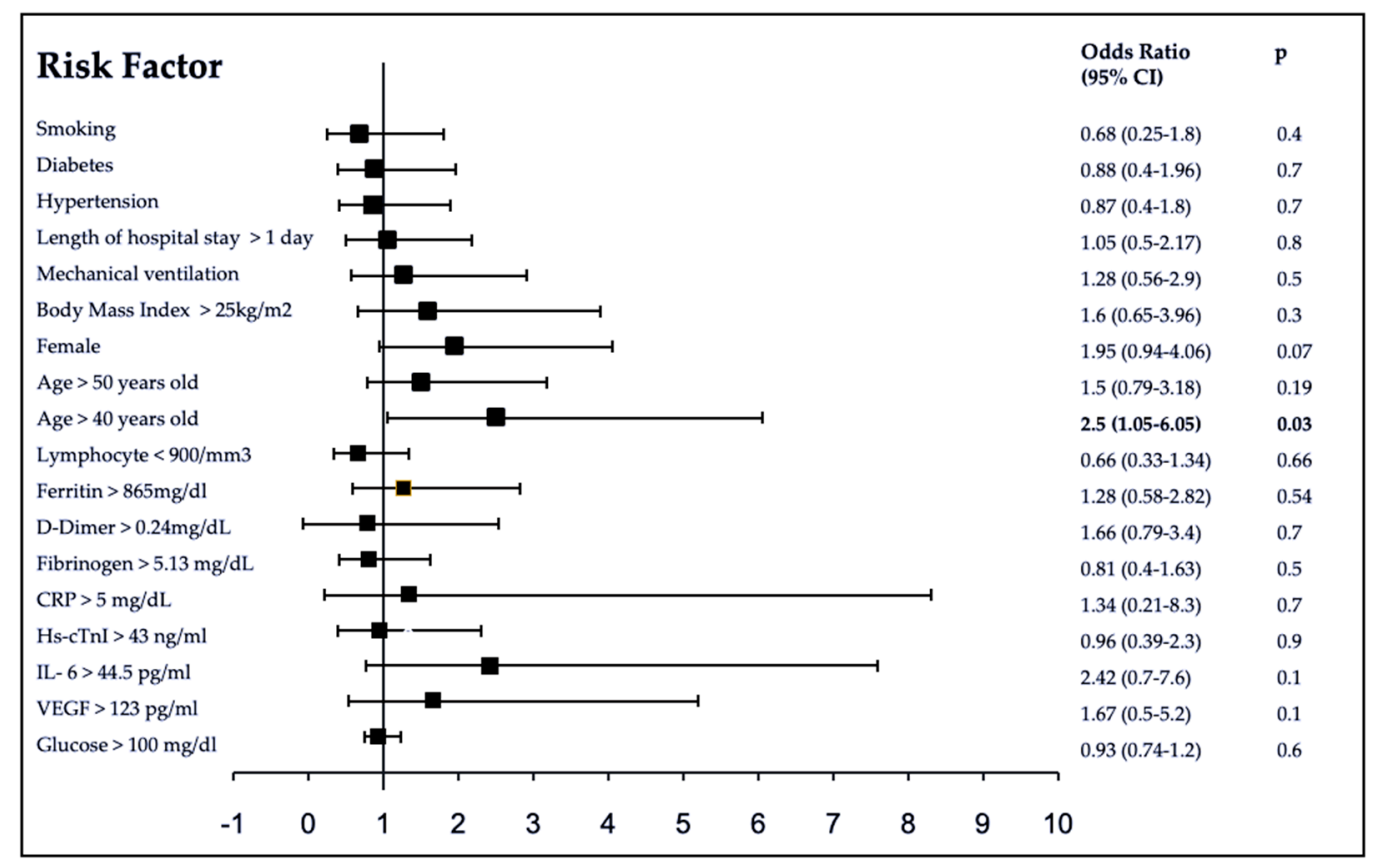

Figure 2. Associated factors in Chronic Fatigue in Post COVID-19. The 95\% confidence intervals (CI) of the odds ratios have been adjusted for multiple testing. In bold, independent predictors associated with the outcomes. To the purpose of logistic regression, variables were categorized regarding their 75-percentiles or lowest levels where 25-percentiles were used of our population. C-Reactive Protein (CRP), High sensitive cardiac Troponin I (hs-cTnI), Interleukin-6 (IL-6), Vascular Endothelial Growth Factor (VEGF).

\section{Discussion}

In our study of 130 patients who were evaluated 3 and 6 months after hospitalization for COVID-19, 91.5\% reported at least 1 symptom that did not exist before the infection. In a recent systematic review to assess the frequency and variety of persistent symptoms among patients with COVID-19, based on PubMed and Web of Science search, 16 studies, most of which comprised patients who were previously hospitalized, reported the persistence of at least 1 symptom with a median frequency of $72.5 \%$ (IQR, 55.0-80.0\%) [27]. We found that the most common symptoms in our patients were fatigue, new-onset dyspnea, sleeping and neurocognitive disturbances, orthostatic intolerance, anxiety, depression, and muscle and joint pain.

We observed fatigue in 69 (53\%) of COVID-19 survivors. Nasserie et al. [27], reported that fatigue was frequently experienced by patients with persistent symptoms after COVID19 (median frequency $40.0 \%$, IQR, 31.0-57.0\%). In our survey, patients with fatigue were older, and persistent fatigue at 3 and 6 months was significantly associated with ages 40 to 50 years old. This finding is comparable with the systematic review by Nasserie et al. [27] where 30 studies reported mean or median age younger than 60 years, and 14 studies reported mean or median ages of 50 years or younger. Carvalho-Schneider et al. [5] described the clinical evolution and predictors of symptom persistence during 2 months of follow-up in adults with noncritical COVID-19, and persistent symptoms at 60 days were significantly associated with ages 40 to 60 years old. 
All the other baseline characteristics (including gender, comorbidities, and laboratory studies) of patients in our cohort showed no statistical difference in those with persistent fatigue compared with those who did not have it.

The available data regarding the incidence and evolution of post COVID symptoms are scarce and heterogeneous. In Italy, Carfi et al. [1] reported persistence of symptoms in $87.4 \%$ of 143 patients discharged from hospital who recovered from acute COVID-19 at a mean follow-up of 60 days from the onset of the first symptom. Fatigue (53.1\%), dyspnea (43.4\%), joint pain (27.3\%), and chest pain $(21.7 \%)$ were the most commonly reported symptoms, with $32 \%$ reporting 1 or 2 symptoms, while $55 \%$ of patients continued to experience 3 or more symptoms. Halpin et al. [4] in the United Kingdom reported the results of a structured telephone interview in 100 patients with a mean of 48 days post discharge from hospital, their findings were similar to ours, fatigue was the most commonly reported symptom by $72 \%$ of participants. The next most common symptoms were breathlessness $(65.6 \%)$ and psychological distress $(46.9 \%)$.

Although psychological distress was not examined in our study with a standardized scale or questionnaire, the frequencies of depression and anxiety were higher than those reported by other studies (35.3\% and 39.2\% respectively), while in other Mexican studies, depression was found in $15.7 \%$ and anxiety in $22.6 \%$ of respondents [23].

An important finding in our study is that the prevalence of symptoms seems to progressively decrease over time. At 6 months post-discharge interview, fatigue declined from $69(53 \%)$ to $61(46.9 \%)$ patients. Wang et al. [28] evaluated 131 COVID-19 patients (median age 49 ) weekly for up to 4 weeks. At discharge, $40.4 \%$ had symptoms, which progressively declined to $9.1 \%$ after 4 weeks.

Fatigue is a multidimensional health problem. As demonstrated in our study, those patients with fatigue had a higher prevalence of other symptoms such as breathlessness, cognitive dysfunction, sleep disturbances, autonomic dysregulation, and psychological distress. The rates of post-COVID fatigue in this and previous studies appear to be higher than those previously reported following other viral infections at a similar interval time [29]. Some of the symptoms of post-COVID syndrome, such as fatigue, myalgia, cognitive disturbances, unrefreshing sleep, orthostatic intolerance, exaggerated postural tachycardia, and hyperadrenergic surges are suggestive of autonomic dysfunction such as those seen in ME/CFS. Although these symptoms parallel those that are seen in postinfectious ME/CFS, data supporting COVID-19 as an infectious trigger for ME/CFS are limited. An observational study investigating post-acute-COVID-19 symptoms as defined by ME/CFS criteria does not yet exist [30]. To date, only a few case reports of confirmed or probable ME/CFS after COVID-19 have been published [31]. Orthostatic intolerance is a hallmark clinical characteristic of ME/CFS. Most symptoms of orthostatic intolerance are related to a reduced cerebral blood flow [32]. Novak [33], described a post COVID-19 patient who developed chronic fatigue, orthostatic dizziness, and brain fog consistent with orthostatic hypoperfusion syndrome (OCHOS), a form of orthostatic intolerance. Dani et al. [34] described a series of individuals with symptoms of long COVID with orthostatic intolerance. In our study, $39.2 \%$ of patients developed after hospitalization orthostatic dizziness and $16.9 \%$ developed lightheadedness after prolonged hospitalization.

Although less frequent compared to inflammatory and immune-mediated disorders, infectious diseases may also affect the autonomic nervous system. There are several pathogenic mechanisms that explain why infections can induce autonomic dysfunction, including the direct invasion of the central nervous system resulting in increased central sympathetic outflow, the involvement of the peripheral autonomic system, and a toxinmediated effect. Immune-mediated mechanism occurring during or after an infection is a well-known trigger of some autonomic neuropathies. SARS-CoV-2 might also infect and destroy extra cardiac postganglionic sympathetic noradrenergic neurons resulting in splanchnic venous pooling or a failure of mesenteric vasoconstriction during orthostasis, secondarily increasing cardiac sympathetic noradrenergic efferent traffic with postural tachycardia syndrome [35]. It has been well established that autonomic disorders, such 
as ME/CFS and postural orthostatic tachycardia syndrome are associated with autoantibodies to $ß 2$ adrenoceptors, which could cause $ß 2$ adrenergic receptor dysfunction and the consequent involvement in their pathophysiology [36]. Recently, novel hypotheses have proposed virus-induced alterations in mitochondrial metabolism [37] and autoimmune systems [38]. These hypotheses are related to some pathophysiologic features involving impairment on the central and autonomic nervous system, metabolic function and the immune system [39].

$\mathrm{ME} / \mathrm{CFS}$ has been associated with viral infections so COVID-19 patients could also develop this illness. Since the first recognition of ME/CFS in a poliomyelitis outbreak in 1934, the illness has undergone various changes in terminology and case definition. Nowadays, the diagnoses of ME and CFS are based upon subjective symptoms reported by patients. According to the published case definitions of ME/CFS, we allocated the most prominent definitions into categories based on the symptoms' characteristics. It was shown in our study that $17.6 \%$ met the commonly used Fukuda criteria for ME/CFS [13], while only $13 \%$ fulfill the more stringent criteria proposed by the Institute of Medicine [16].

"Long COVID-19" was first used as a Twitter hashtag to describe persistent symptoms after acute COVID-19; following intense advocacy by patients across the world, the WHO adopted this patient-coined term. The so-called long COVID-19 or if preferred post-acute COVID-19 syndrome may well include several conditions that have more than one etiology and may last a long time in the same patient.

\section{Limitations}

The study has several limitations. It was conducted in a relatively small sample size at a tertiary single care center, with telephonic interviews using a binary questionnaire. Therefore, our results could not be accurate to diagnose ME/CFS. This investigation was an uncontrolled cohort study, which precludes any comparison of findings with individuals not experiencing COVID-19. Several patients who were asked to participate declined telephone surveys: it is possible that patients who did not participate were less symptomatic than those who did. The findings are also limited by the lack of imaging studies to evaluate residual lung, myocardial or brain involvement which could explain the symptoms.

\section{Conclusions}

The current study represents, to our knowledge, a novel report in literature examining the potential relationship between the symptoms of post-acute COVID-19 Syndrome and $\mathrm{ME} / \mathrm{CFS}$ in a large cohort.

This study demonstrated that significant abnormalities still exist in a high proportion of COVID-19 patients up to 6 months after discharge. It is necessary to follow-up these patients, performing comprehensive assessment and early rehabilitation for detection and appropriate management of persistent or emerging long-term symptoms. The full range of the duration and severity of post-acute COVID-19 is currently unknown. A consensus is needed regarding when and how to classify manifestations in the post-acute period, considering many of these symptoms may resolve with time and their prevalence, therefore, depends on the time of evaluation [40]. Longer longitudinal studies and further research would be required to understand the mechanisms underlying long-term COVID19 symptoms and their precise connection with ME/CFS.

Author Contributions: Conceptualization, J.A.G.-H.; Data curation, S.A.C.-L., D.R.-O., S.H.-R. and L.M.A.-G.; Formal analysis, J.P.M.-L. and M.d.R.M.-A.; Investigation, J.A.G.-H., S.A.C.-L., D.R.-O., S.H.-R. and L.M.A.-G.; Methodology, J.P.M.-L. and M.d.R.M.-A.; Resources, J.A.G.-H., S.A.C.-L., D.R.-O., S.H.-R. and L.M.A.-G.; Software, J.P.M.-L. and M.d.R.M.-A.; Validation, J.P.M.-L. and M.d.R.M.-A.; Writing—original draft, J.A.G.-H.; Writing—review \& editing, J.P.M.-L., S.A.C.-L., D.R.-O., S.H.-R., L.M.A.-G. and M.d.R.M.-A. All authors have read and agreed to the published version of the manuscript. 
Funding: This research received no external funding. The Instituto Nacional de Cardiología Ignacio Chavez supported Open Access funding.

Institutional Review Board Statement: Ethical review and approval were waived for this study, due to minimal risks characteristics of an observational survey.

Informed Consent Statement: Informed consent was obtained verbally from all subjects involved in the study, before the survey began.

Data Availability Statement: This study did not report any data. The study was conducted in accordance with the Declaration of Helsinki.

Acknowledgments: We want to thank the contribution of Betty Lou Chinn R.N for the grammatical review of the manuscript.

Conflicts of Interest: The authors declare no conflict of interest.

\section{References}

1. Carfi, A.; Bernabei, R.; Landi, F. Gemelli against COVID-19 post-acute care study Group. Persistent symptoms in patients alter acute COVID-19. JAMA 2020, 24, 603-605. [CrossRef] [PubMed]

2. Xiong, Q.; Xu, M.; Li, J.; Liu, Y.; Zhang, J.; Xu, Y.; Dong, W. Clinical sequelae of COVID-19 survivors in Wuhan, China: A single-centre longitudinal study. Clin. Microbiol. Infect. 2021, 27, 89-95. [CrossRef] [PubMed]

3. Tenforde, T.W.; Kim, S.S.; Lindsell, C.J.; Rose, E.B.; Shapiro, N.I.; Files, D.C.; Gibbs, K.W.; Erickson, H.L.; Steingrub, J.S.; Smithline, H.A.; et al. Symptom duration and risk factors for delayed return to usual health among outpatients with COVID-19 in a multi state health care systems network-United States. March-June 2020. Morb. Mortal. Wkly. Rep. 2020, 69, 993-998. [CrossRef] [PubMed]

4. Halpin, S.J.; McIvor, C.; Whyatt, G.; Adams, A.; Harvey, O.; McLean, L.; Walshaw, C.; Kemp, S.; Corrado, J.; Singh, R.; et al. Postdischarge symptoms and rehabilitation needs in survivors of COVID-19 infection: A cross-sectional evaluation. J. Med. Virol. 2021, 93, 1013-1022. [CrossRef] [PubMed]

5. Carvalho-Schneider, C.; Laurent, E.; Lemaignen, A.; Beaufils, E.; Bourbao-Tournois, C.; Laribi, S.; Flament, T.; Ferreira-Maldent, N.; Bruyère, F.; Stefic, K.; et al. Follow-up of adults with noncritical COVID-19 two months after symptom onset. Clin. Microbiol. Infect. 2021, 27, 258-263. [CrossRef] [PubMed]

6. Huang, C.; Huang, L.; Wang, Y.; Li, X.; Ren, L.; Gu, X.; Kang, L.; Guo, L.; Liu, M.; Zhou, X.; et al. 6-month consequences of COVID-19 in patients discharged from hospital: A cohort study. Lancet 2021, 397, 220-232. [CrossRef]

7. Ahmed, H.; Patel, K.; Greenwood, D.C.; Halpin, S.; Lewthwaite, P.; Salawu, A.; Eyre, L.; Breen, A.; O'connor, R.; Jones, A.; et al. Long term clinical outcomes in survivors of severe acute respiratory syndrome (SARS) and middle east respiratory syndrome (MERS) coronavirus out breaks alter hospitalization or ICU admission: A systematic review and meta-analysis. J. Rehabil. Med. 2020, 52, 1-11. [CrossRef]

8. Goërtz, Y.M.J.; Van Herck, M.V.; Delbressine, J.M.; Vaes, A.W.; Meys, R.; Machado, F.V.C.; Houben-Wilke, S.; Burtin, C.; Posthuma, R.; Franssen, F.M.E.; et al. Persistent symptoms 3 months alter a SARS-CoV-2 infection: The post-COVID-19 syndrome? ERJ Open Res. 2020. [CrossRef]

9. Townsend, L.; Dyer, A.H.; Jones, K.; Dunne, J.; Mooney, A.; Gaffney, F.; O'Connor, L.; Leavy, D.; O’Brien, K.; Dowds, J.; et al. Persistent fatigue following SARS-CoV-2 infection is common and independent of severity of initial infection. PLoS ONE 2020, 15, e0240784. [CrossRef]

10. Lopez-Leon, S.; Wegman-Ostrosky, T.; Perelman, C.; Sepulveda, R.; Rebolledo, P.A.; Cuapio, A.; Villapol, S. More than 50 Long-term effects of COVID-19: A systematic review and meta-analysis. medRxiv 2021. preprint. [CrossRef]

11. Magnus, P.; Gunnes, N.; Tveito, K.; Bakken, I.J.; Ghaderi, S.; Stoltenberg, C.; Hornig, M.; Lipkin, W.I.; Trogstad, L.; Håberg, S.E. Chronic fatigue syndrome/myalgic encephalomyelitis (CFS/ME) is associated with pandemic influenza infection, but not with an adjuvanted pandemic influenza vaccine. Vaccine 2015, 33, 6173-6177. [CrossRef]

12. Katz, B.Z.; Shiraishi, Y.; Mears, C.J.; Binns, H.J.; Taylor, R. Chronic Fatigue Syndrome after Infectious Mononucleosis in Adolescents. Pediatrics 2009, 124, 189-193. [CrossRef]

13. Fukuda, K.; Straus, S.E.; Hickie, I.; Sharpe, M.C.; Dobbins, J.G.; Komaroff, A. The Chronic Fatigue Syndrome: A Comprehensive Approach to Its Definition and Study. Ann. Intern. Med. 1994, 121, 953-959. [CrossRef]

14. Carruthers, B.M.; Jain, A.K.; De Meirleir, K.L.; Peterson, D.L.; Klimas, N.G.; Lemer, A.M.; Bested, A.C.; Flor-Henry, P.; Joshi, P.; Powles, A.C.P.; et al. Myalgic encephalomyelitis/chronic fatigue syndrome: Clinical working case definition, diagnostic and treatment protocols (Canadian case definition). J. Chronic Fatigue Syndr. 2003, 11, 7-115. [CrossRef]

15. Carruthers, B.M.; van de Sande, M.I.; De Meirleir, K.L.; Klimas, N.G.; Broderick, G.; Mittche, T.; Stainess, D.; Powles, A.C.P.; Speight, N.; Vallings, R.; et al. Myalgic Encephalomyelitis: International Consensus Criteria. J. Intern. Med. 2011, 270, 327-338. [CrossRef]

16. Institute of Medicine. Beyond Myalgic Encephalomyelitis/Chronic Fatigue Syndrome: Redefining an Illness; Report Guide for Clinicians; The National Academies: Washington, DC, USA, 2015. 
17. Brurberg, K.G.; Fønhus, M.S.; Larun, L.; Flottorp, S.; Malterud, K. Case definitions for chronic fatigue syndrome/myalgic encephalomyelitis (CFS/ME): A systematic review. BMJ Open 2014, 4, e003973. [CrossRef]

18. Davis, H.E.; Assaf, G.S.; McCorkell, L.; Wei, H.; Low, R.J.; Re'em, Y.; Redfield, S.; Austin, J.P.; Akrami, A. Characterizing Long COVID in an International Cohort: 7 Months of Symptoms and Their Impact. medRxiv 2020, 20248802. [CrossRef]

19. Słomko, J.; Newton, J.L.; Kujawski, S.; Tafil-Klawe, M.; Klawe, J.; Staines, D.; Marshall-Gradisnik, S.; Zalewski, P. Prevalence and characteristics of chronic fatigue syndrome/myalgic encephalomyelitis (CFS/ME) in Poland: A cross-sectional study. BMJ Open 2019, 9, e023955. [CrossRef]

20. Komaroff, A.L.; Bateman, L. Will COVID-19 Lead to Myalgic Encephalomyelitis/Chronic Fatigue Syndrome? Front. Med. 2021, 7, 606824. [CrossRef]

21. Perrin, R.; Riste, L.; Hann, M.; Walther, A.; Mukherjee, A.; Heald, A. Into the looking glass: Post-viral syndrome post COVID-19. Med. Hypotheses 2020, 144, 110055. [CrossRef]

22. Casagrande, M.; Favieri, F.; Tambelli, R.; Forte, G. The enemy who sealed the world: Effects quarantine due to the COVID-19 on sleep quality, anxiety, and psychological distress in the Italian population. Sleep Med. 2020, 75, 12-20. [CrossRef]

23. Cortés-Alvarez, N.Y.; Piñeiro-Lamas, R.; Vuelvas-Olmos, C. Psychological Effects and Associated Factors of COVID-19 in a Mexican Sample. DMAPHP 2020. [CrossRef]

24. Nalbandian, A.; Sehgal, K.; Gupta, A.; Madhavan, M.; McGroder, C.; Stevens, J.; Cook, J.; Nordving, A.; Shalev, D.; Sehrawat, T. Post-acute COVID-19 syndrome. Nat. Med. 2021, 27, 601-615. [CrossRef]

25. World Health Organization. Clinical Management of Severe Acute Respiratory Infection (SARI) When COVID-19 Disease Is Suspected: Interim Guidance, 13 March 2020. Licence CC BY-NC-SA 3.0 IGO. World Health Organization, 2020. Available online: https: / / apps.who.int/iris/handle/10665/331446 (accessed on 30 May 2021).

26. Rivera, M.C.; Mastronardi, C.; Silva-Aldana, C.T.; Arcos-Burgos, M.; Lidbury, B.A. Myalgic Encephalomyelitis/Chronic Fatigue Syndrome: A Comprehensive Review. Diagnostics 2019, 9, 91. [CrossRef]

27. Nasserie, T.; Hittle, M.; Goodman, S.N. Assessment of the Frequency and Variety of Persistent Symptoms among Patients with COVID-19. JAMA 2021, 4, e2111417. [CrossRef]

28. Wang, X.; Xu, H.; Jiang, H.; Wang, L.; Lu, C.; Wei, X.; Liu, J.; Xu, S. Clinical features and outcomes of discharged coronavirus disease 2019 patients: A prospective cohort study. QJM 2020, 113, 657-665. [CrossRef]

29. Hickie, I.; Davenport, T.; Wakefield, D.; Vollmer-Conna, U.; Cameron, B.; Vernon, S.D.; Reeves, W.C.; Lloyd, A. Post-infective and chronic fatigue syndromes precipitated by viral and non-viral pathogens: Prospective cohort study. BMJ 2006, $333,575$. [CrossRef]

30. Poenaru, S.; Abdallah, S.; Corrales-Medina, V.; Cowan, J. COVID-19 and post-infectious myalgic encephalomyelitis/chronic fatigue syndrome: A narrative review. SAGE J. 2021. [CrossRef]

31. Petracek, L.; Suskauer, S.; Vickers, R.; Patel, N.; Violand, R.; Swope, R.; Rowe, P. Adolescent and Young Adult ME/CFS after Confirmed or Probable COVID-19. Front. Med. 2021, 8, 668944. [CrossRef]

32. Miwa, K. Variability of postural orthostatic tachycardia in patients with myalgic encephalomyelitis and orthostatic intolerance. Heart Vessel. 2016, 31, 1522-1528. [CrossRef]

33. Novak, P. Post COVID-19 syndrome associated with orthostatic cerebral hypoperfusion syndrome, small fiber neuropathy and benefit of immunotherapy: A case report. eNeurologicalSci 2020, 21, 100276. [CrossRef] [PubMed]

34. Dani, M.; Dirksen, A.; Taraborrelli, P.; Torocastro, M.; Panagopoulos, D.; Sutton, R.; Lim, P.B. Autonomic dysfunction in 'long COVID': Rationale, physiology and management strategies. Clin. Med. 2021, 21, e63-e67. [CrossRef]

35. Goldstein, D.S. The possible association between COVID-19 and postural tachycardia syndrome. Heart Rhythm. 2021, 18, 508-509. [CrossRef] [PubMed]

36. Vernino, S.; Stiles, L.E. Autoimmunity in postural orthostatic tachycardia syndrome: Current understanding. Auton. Neurosci. 2018, 215, 78-82. [CrossRef]

37. Filler, K.; Lyon, D.; Bennett, J.; McCain, N.; Elswick, R.; Lukkahatai, N.; Saligan, L.N. Association of mitochondrial dysfunction and fatigue: A review of the literature. BBA Clin. 2014, 1, 12-23. [CrossRef]

38. Blomberg, J.; Gottfries, C.-G.; Elfaitouri, A.; Rizwan, M.; Rosén, A. Infection Elicited Autoimmunity and Myalgic Encephalomyelitis/Chronic Fatigue Syndrome: An Explanatory Model. Front. Immunol. 2018, 9, 229. [CrossRef]

39. Komaroff, A.L. Advances in Understanding the Pathophysiology of Chronic Fatigue Syndrome. JAMA 2019, 322, 499. [CrossRef]

40. Moreno-Pérez, O.; Merino, E.; Leon-Ramirez, J.M.; Andres, M.; Ramos, J.M.; Arenas-Jiménez, J.; Asensio, S.; Sanchez, R.; Ruiz-Torregrosa, P.; Galan, I.; et al. Post-acute COVID-19 syndrome. Incidence and risk factors: A Mediterranean cohort study. J. Infect. 2021, 82, 378-383. [CrossRef] 